\title{
Assessment of Toxicity and Therapeutic Effects of Goose Bone in a Rat Model
}

\author{
Md. Yousuf Ali $\mathbb{D}^{1},{ }^{1}$ Alamgir Kabir, ${ }^{1}$ Shahad Saif Khandker, ${ }^{1}$ Tareq Hossan, \\ Md. Salman Shakil, ${ }^{1}$ Md. Aminul Islam $\mathbb{D}^{1},{ }^{1}$ Md. Ashraful Hasan, ${ }^{1}$ Md. Sakib Hossen $\mathbb{D}^{1}{ }^{1}$ \\ Siew Hua Gan $\mathbb{D}^{2}$, and Md. Ibrahim Khalil $\mathbb{D}^{1}$ \\ ${ }^{1}$ Laboratory of Preventive and Integrative Biomedicine, Department of Biochemistry and Molecular Biology, \\ Jahangirnagar University, Savar, Dhaka 1342, Bangladesh \\ ${ }^{2}$ School of Pharmacy, Monash University Malaysia, Jalan Lagoon Selatan, 47500 Bandar Sunway, Selangor, Malaysia
}

Correspondence should be addressed to Siew Hua Gan; gan.siewhua@monash.edu and Md. Ibrahim Khalil; drmikhalil@gmail.com Received 17 December 2018; Accepted 7 October 2019; Published 29 October 2019

Academic Editor: José L. Arias Mediano

Copyright $\odot 2019 \mathrm{Md}$. Yousuf Ali et al. This is an open access article distributed under the Creative Commons Attribution License, which permits unrestricted use, distribution, and reproduction in any medium, provided the original work is properly cited.

Goose bone is traditionally used in the treatment of many ailments including in bone fracture. The aim of the present study was to evaluate the subacute toxicity of goose bone in a rat model by investigating some hematological and biochemical parameters in rats. Subsequently, a histopathological study was performed to confirm the presence of pathological lesions in the rat's vital organs including the liver, kidney, heart, brain, pancreas, lung, spleen, and stomach. Adult Wistar rats were divided into four groups $(n=8)$ and were orally administrated with three doses $(30,60$, and $120 \mathrm{mg} / \mathrm{kg})$ of goose bone once daily for 21 days as compared to control animals (received only drinking water). Goose bone did not cause any significant changes on body weight, relative organ weight, and percentage water content at any of the administered doses. There were also no significant alterations in hematological parameters seen. All three doses administered significantly reduced the triglyceride levels as well as the atherogenic index of plasma (AIP). Animals treated with $120 \mathrm{mg} / \mathrm{kg}$ doses had significantly reduced alkaline phosphatase (ALP) activity as compared to the control group. There was no significant alteration on other serum biochemical parameters seen. Additionally, histopathological findings confirmed that there was no inflammatory, necrotic, or other toxicological feature seen for all three doses. It is concluded that goose bone is nontoxic and is safe for consumption besides having the potential to be investigated for the treatment of high triglycerides or liver-related disorder.

\section{Introduction}

From ancient times, various traditional drugs have been utilized in the treatment of several chronic diseases not only for curing but also for prevention of diseases. Goose bone is a traditional remedy utilized in Malay traditional medicine for several years. It has been widely applied for both external and internal complications, especially in the treatment of fractured bones. Nutritionally, goose bone is rich in protein (35\%), carbohydrate (6\%), fat (11\%), and dietary fiber (5\%). Additionally, there is also high calcium (14.6\%) content with some other essential minerals including sodium $(0.41 \%)$, potassium $(0.14 \%)$, and iron $(0.004 \%)$ identified. The folklore claims on its use may be substantiated by the fact that calcium is an important mineral for the bones, joints, nerve, and muscle [1-3].

Besides bone fractures, it is also believed that regular consumption of goose bone can boost the immune system. Goose bone is traditionally applied to ameliorate fever, particularly in children. Nowadays, goose bone is processed into powder and is inserted into capsules which are used for treatment. Nevertheless, although goose bone treatment is very popular in folk medicine, there are no scientific data to support its use or to evaluate its toxic effects. Therefore, the aim of this study is to assess the possible toxic effect of goose bone in a rat model by investigating the biochemical, hematological, and histopathological parameters. 


\section{Materials and Methods}

2.1. Chemicals and Reagents. Ketamine hydrochloride injection was purchased from Popular Pharmaceuticals Ltd., Dhaka, Bangladesh. All chemicals and reagents used were of analytical grade.

2.2. Preparation of Goose Bone. The geese (Anserinae anserine) were reared under a tropical environment, in a farmhouse located in Pasir Mas, Kelantan, Malaysia. The geese were fed with mixtures of bran, inner husk of grain, sago (starchy food in hard white grains), vegetables, and rice. The geese were allowed water ad libitum. The geese were ready to be slaughtered based on an Islamic law or "halal" manner when they were one year old. Animals of both genders were used, as long as they have reached the optimum age and appeared to be of an average size of an adult goose.

Then, the geese were slaughtered and the bones were separated from the meat. For powder preparation, only the bones were used. The bones (except for the head and the feet) were burned, crushed, and grinded until it became a fine powder and the color turned blackish. Goose bone powder was prepared in a dry environment to avoid fungal growth and oxidization. Subsequently, the powder was inserted into hard-shelled capsules purchased from pharmacies and was packed in a plastic bottle together with a silica gel substance to preserve it. The capsules have been patented (PI2017701257).

2.3. Experimental Animals. Adult Wistar rats of both sexes (150 to $250 \mathrm{~g}$ ) at $16-18$ weeks were utilized. Animals were bred and reared in the animal house at the Department of Biochemistry and Molecular Biology, Jahangirnagar University, at a constant temperature $\left(23 \pm 2^{\circ} \mathrm{C}\right)$ and humidity ( $44 \%$ to $56 \%$ ). The rats were kept in sterile plastic cages containing soft wood-chip bedding and were exposed to a natural $12 \mathrm{~h}$ day-night cycle. The rats were allowed free supply of water and a standard laboratory pellet diet. The experimental protocol was approved by the Biosafety, Biosecurity and Ethical Committee of Jahangirnagar University, Savar, Dhaka, Bangladesh (ethical number: BBEC,JU/M2019 (7) 4) which was in agreement with the internationally established principles of the US guidelines.

2.4. Experimental Design. The rats $(n=32)$ were familiarized to the lab environment 7 days before experimentation. The animals were allotted into four groups ( $n=8$ rats each) with a balance mix of gender [4].

Group A (normal control): rats were given a normal diet and water ad libitum.

Group B (treatment 1): rats administered with goose bone $(30 \mathrm{mg} / \mathrm{kg})$ dissolved in normal saline for 21 days (again, all rats were given a normal diet and water $a d$ libitum).

Group C (treatment 2): rats administered with goose bone $(60 \mathrm{mg} / \mathrm{kg})$ dissolved in normal saline for 21 days (again, all rats were given a normal diet and water $a d$ libitum).

Group D (treatment 3): rats administered with goose bone $(120 \mathrm{mg} / \mathrm{kg})$ dissolved in normal saline for 21 days (again, all rats were given a normal diet and water ad libitum).

The doses were chosen based on the normal doses taken by human which is approximately $500 \mathrm{mg} /$ day. Calculation of dose in animals based on human dose was done according to the formula as suggested by Reagan-Shaw et al. [5]:

$$
\begin{aligned}
& \text { human equivalent dose }(\mathrm{mg} / \mathrm{kg})=\text { rat's dose }(\mathrm{mg} / \mathrm{kg}) \times\left(\frac{\text { Rat } K_{\mathrm{m}}}{\text { human } K_{\mathrm{m}}}\right), \\
& \text { rat's dose }(\mathrm{mg} / \mathrm{kg})=\frac{\text { human equivalent dose }(\mathrm{mg} / \mathrm{kg})}{\left(\text { rat } K_{\mathrm{m}} / \text { human } K_{\mathrm{m}}\right)}, \\
& \text { rat's dose }(\mathrm{mg} / \mathrm{kg})=\frac{8.33(\mathrm{mg} / \mathrm{kg})}{(6 / 37)}\left[\frac{500 \mathrm{mg}}{60 \mathrm{~kg}}=8.33 \mathrm{mg} / \mathrm{kg}\right], \\
& \text { rat's dose }(\mathrm{mg} / \mathrm{kg})=51.37 \mathrm{mg} / \mathrm{kg},
\end{aligned}
$$

where $K_{\mathrm{m}}=$ correction factor which is estimated by dividing the average body weight $(\mathrm{kg})$ of the species to its body surface area $\left(\mathrm{m}^{2}\right)$. Assuming the average human body weight is $60 \mathrm{~kg}$ with a body surface area of $1.62 \mathrm{~m}^{2}, K_{\mathrm{m}}$ factor for human is calculated by dividing 60 by 1.62 , which is 37 (the $K_{\mathrm{m}}$ value for human is 37 and that for rat is 6).
Based on the calculated dose of $51.37 \mathrm{mg} / \mathrm{kg}$, a rounded value at $60 \mathrm{mg} / \mathrm{kg}$ was taken as the middle dose range. From this value, the low dose of $30 \mathrm{mg} / \mathrm{kg}$ and a high dose at $120 \mathrm{mg} / \mathrm{kg}$ were selected. During the experimental period, the animals were monitored for behavioral changes in their feeding and drinking habits and for some physiological 
changes including reduced activity and diarrhea in order to detect any sign of abnormalities.

2.5. Harvesting of Organs. At the completion of the experiment, the animals were not given any food or water for one day before ketamine hydrochloride injection $(500 \mathrm{mg} / \mathrm{kg})$ [6] via the intraperitoneal veins. Subsequently, blood $(5 \mathrm{~mL})$ was taken from the inferior vena cava and was transferred to two tubes. The first tube contained ethylene diamine tetraacetic acid (EDTA) for hematological analyses while the second tube was a plain tube for serum biochemical analyses. The harvested organs were weighed and were kept in $10 \%$ formalin for subsequent histopathological examination.

2.6. Measurement of Body and Relative Organ Weights as well as Percentage Water Content. The animal's body weights were measured weekly throughout the experimental period. For measurement of relative organ weight and percentage of water content, tissue samples (liver, kidney, heart, lung, spleen, caecum, pancreas, brain, testes, thymus, caput, stomach, ovary, cowper's gland, and fallopian tube) were removed and weighed as soon as sacrifice. The relative organ weight was estimated by dividing the weight of each organ with the final body weight of each animal based on the following formula [7]:

$$
\text { relative organ weight }(\%)=\frac{\text { weight of wet organ }}{\text { rat's body weight }} \times 100 \text {. }
$$

The percentage of water content was estimated based on every wet organ by subtracting the dry weight of each organ, respectively [8].

2.7. Preparation of Serum. Following sacrifice, the blood samples were transferred to dry test tubes and were left to coagulate naturally for approximately $30 \mathrm{~min}$. Serum was yielded following centrifugation $(2000 \mathrm{rpm} \times 10 \mathrm{~min})$.

2.8. Hematological Parameters. The blood parameters were analyzed using an automated hematology analyzer (8000i, Sysmex, Japan) for all groups. These included determination of eosinophils, neutrophils, white blood cells (WBCs), monocytes, lymphocytes, red blood cells (RBCs), hemoglobin (HGB), hematocrit (HCT), mean corpuscular volume $(\mathrm{MCV})$, mean corpuscular hemoglobin $(\mathrm{MCH})$, platelets (PLT), mean corpuscular hemoglobin concentration (MCHC), erythrocyte sedimentation rate (ESR), red cell distribution width-standard deviation (RDW-SD), red cell distribution width-coefficient of variation (RDW-CV), mean platelets volume (MPV), platelets distribution width (PDW), platelets larger cell ratio (P-LCR), and procalcitonin (PCT).

2.9. Serum Biochemical Analysis. Liver function tests (aspartate transaminase (AST), alanine transaminase (ALT), alkaline phosphatase (ALP), $\gamma$-glutamyltransferase (GGT), lactate dehydrogenase (LDH), total protein (TP), total bilirubin (TB), albumin (ALB), globulin (GLB), and albumin/ globulin (A/G) ratio); kidney function tests (uric acid, urea, and creatinine); lipid profiles (triglycerides (TG), total cholesterol (TC), and high-density lipoprotein cholesterol (HDL-C)), serum electrolytes including sodium $\left(\mathrm{Na}^{+}\right)$, chloride $\left(\mathrm{Cl}^{-}\right)$, potassium $\left(\mathrm{K}^{+}\right)$, calcium $\left(\mathrm{Ca}^{2+}\right)$, magnesium $\left(\mathrm{Mg}^{2+}\right)$, and phosphate $\left(\mathrm{PO}^{4+}\right)$ ions, pancreatic function tests (the enzymes such as lipase and amylase), and also glycemic condition such as serum glucose (GLU) concentrations were established based on standard tests using an automated chemistry analyzer (Dimension EXL with LM Integrated Chemistry System, Siemens Medical Solutions Inc., USA). Another important factor lipid profile such as serum low-density lipoprotein cholesterol (LDL-C) level was established according to the Friedewald formula [9]:

$$
\text { LDL-C }=\frac{\text { TC }- \text { HDL-C }- \text { TG }}{5} .
$$

Atherogenic indices including cardiac risk ratio (CRR), atherogenic index of plasma (AIP), atherogenic coefficient (AC), and Castelli's risk index-2 (CRI-2) were estimated according to the following formulae [10--13]:

$$
\begin{aligned}
\mathrm{CRR} & =\frac{\mathrm{TC}}{\mathrm{HDL}-\mathrm{C}}, \\
\mathrm{AC} & =\frac{(\mathrm{TC}-\mathrm{HDL}-\mathrm{C})}{\mathrm{HDL}-\mathrm{C}}, \\
\mathrm{AIP} & =\log \left(\frac{\mathrm{TG}}{\mathrm{HDL}-\mathrm{C}}\right), \\
\mathrm{CRI}-2 & =\frac{\text { LDL-C }}{\text { HDL-C }}
\end{aligned}
$$

2.10. Histopathological Findings. The liver, brain, spleen, lung, stomach, kidney, heart, and pancreas tissue samples were fixed in formalin (10\%) followed by paraffin embedding fixing. The specimens were sliced into slices of $5 \mu \mathrm{m}$ thickness by means of a rotary microtome. The specimens were then tainted using hematoxylin and eosin dye [14]. Photomicrographs were taken by using a normal-spectrum fluorescence microscope (Olympus DP 72) at 40x magnification. The microscope was connected to a digital camera (Olympus, Tokyo, Japan). The pathologist who conducted the histopathological examination was unaware to the treatment groups.

2.11. Statistical Analysis. The results were expressed as mean \pm standard deviation (SD). Data were evaluated by using SPSS (version 16.0, IBM Corporation, New York, USA). Data from the treatment groups were evaluated against the control by using a one-way ANOVA followed by Dunnett's multiple comparison tests where $p<0.05$ was deemed as statistically significant. 


\section{Results}

3.1. The Effects of Goose Bone on Body Weight, Relative Organ Weight, and Percent Water Content of Rat's Organs. During the experimental period, rats' body weight increased gradually although these changes were not significantly different from the first to the third week (Figure 1) as compared to the control. There was also no significant difference in both relative organ weight and percentage of water content of different rat's organs (Tables 1 and 2).

\subsection{The Effects of Goose Bone on the Hematological} Parameters. There was no significant difference among the control and treatments groups in terms of hematological parameters (Table 3).

No significant changes were established when all treatment groups were compared against the control group by using one-way ANOVA followed by Dunnett's multiple comparison tests.

\subsection{The Effects of Goose Bone on Serum Biochemical} Parameters. Goose bone did not confer any effects on parameters for liver function including ALT, AST, ALP, GGT, $\mathrm{LDH}$ activities, and TB levels. In fact, ALP levels were significantly decreased at the highest dose $(120 \mathrm{mg} / \mathrm{kg})$ while ALT, AST, TP, ALB, GLB, and A/G which are important biomarkers of liver function remained unchanged at the three dose levels (Figure 2 and Table 4) indicating that goose bone does not affect the function of this major organ and may help to protect against liver damage especially when used in high doses.

The effects of goose bone on the renal function were analyzed by measuring serum urea, uric acid, and creatinine levels and major electrolytes such as $\mathrm{Na}^{+}, \mathrm{K}^{+}, \mathrm{Cl}^{-}, \mathrm{Mg}^{2+}, \mathrm{P}$, and $\mathrm{Ca}^{2+}$ levels (Table 5). All three doses did not significantly affect the biomarkers for renal function or alter body electrolytes levels.

Lipid profiles (TC, TG, HDL-C, and LDL-C) and atherogenic indices (CRR, AC, AIP, and CRI-2) are reliable markers for cardiovascular diseases. Goose bone significantly reduced serum TG levels (Figure 3) and AIP at all three doses (Table 6).

Goose bone did not affect pancreatic function and blood glucose levels where there were no significant changes on the serum amylase, lipase, and glucose levels (Table 7).

3.4. Histopathological Examination. Histopathological examination of the liver, kidney, lung, brain, stomach, pancreas, spleen, and heart did not show any morphological and pathological changes following the administration of goose bone in all three doses $(30,60$, and $120 \mathrm{mg} / \mathrm{kg}$ ) when compared with the control (Figure 4) again confirming its safety on these organs.

\section{Discussion}

To our knowledge, this is the first study to confirm the safety profile of goose bone. Daily oral administration of goose bone in a rat model at 30,60 , and $120 \mathrm{mg} / \mathrm{kg}$ for 21 days did not cause mortality, change in food habit and water intake, body and organ weight, and biochemical findings, confirming that goose bone is safe when administered at these doses. Additionally, there were no histopathological changes in the organs including the liver, kidney, heart, pancreas, stomach, brain, lung, and spleen confirming that goose bone is safe.

Toxic agents are responsible for abnormal metabolic reactions in the body that may alter the growth of animals and cause deposition of water in vital organs like the liver, heart, lung, spleen, brain, kidney, and reproductive organs including the testes, caput, cowper gland (in males), and ovary and fallopian tube (in females) [15]. Therefore, body and relative organ weights as well as percentage water content are important parameters for toxicological studies. In the present study, no significant difference was observed in body and relative organ weights as well as percentage water content were compared with those of the control group during the experimental period indicating that goose bone does not affect these parameters and rats' homeostasis.

Analysis of hematological parameter is important when assessing physiological and pathological conditions in the body. Deprivation, stress, abnormal body metabolic activities, and response of the body to injury or lesions are closely-related with abnormal findings for hematological parameter [16]. In fact, hematological parameters like RBCs, HGB, HCT, MCV, MCH, MCHC, RDW-SD, and RDW-CV can help to unravel important information about anemic condition and other erythrocyte cell-related disorders such as polycythemia and thalassemia. WBCs and its differential count including neutrophils, lymphocytes, eosinophils, monocytes, and basophils play important roles in the immune system in combating infections where the overproduction of these parameters are important hallmarks of inflammation and stress-related disorders $[17,18]$. Platelets and platelet indices including MPV, PDW, and P-LCR are important indicators for early diagnosis of thromboembolic, atherosclerosis, and ischemic heart disease [19-21]. The levels of both ESR and PCT can yield important information about inflammatory condition in the body. In our present study, there were no significant changes in the hematological findings indicating that administration of goose bone causes no toxic effect on the animal's body.

The liver is the major site for detoxification and elimination of toxic substance from the body. Any foreign substances that may affect the liver function can alter ALT, AST, ALP, GGT, TB, TP, ALB, GLB, and albumin-globulin (A/G) ratio activities [22, 23]. Generally, damage to the parenchymal liver cell is associated with elevation of these enzymes in the blood [24]. ALT and AST are the major intracellular cytoplasmic enzymes where their elevation in the serum indicates some injuries in the liver cells [25]. On the other hand, ALP and GGT are indicators for hepatobiliary damage [26] while AST and $\mathrm{LDH}$, mostly found in the heart, liver, kidney, and skeletal muscle, are indicators of both myocardium and hepatocellular injuries [23]. TB indicates liver injury or necrosis and measures the binding, conjugation, and excretory capacities of the hepatocytes 


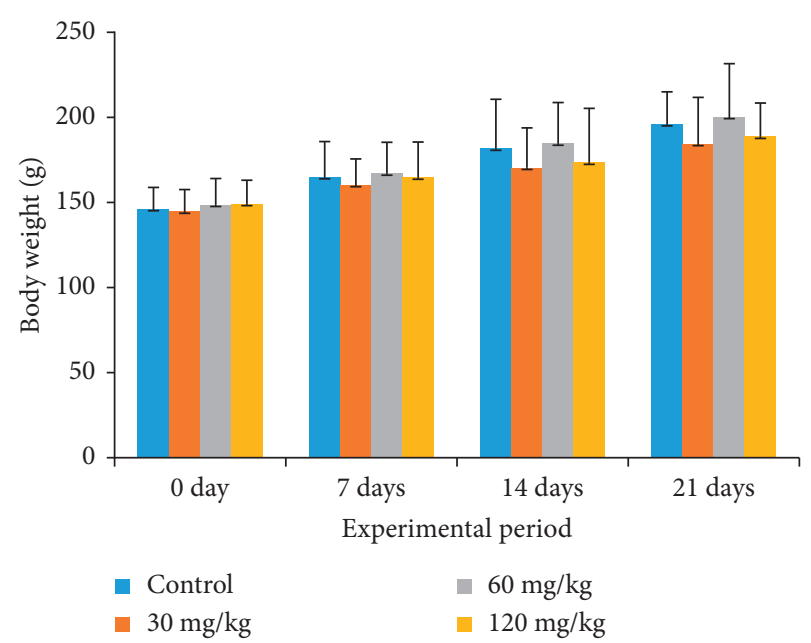

FIGURE 1: The effects of goose bone on body weight (g) gain. Results are expressed as mean $\pm \mathrm{SD}$. $(n=8)$. Nonsignificant changes were found when all treatment groups were compared against the control group $(p<0.05)$ as determined by one-way ANOVA followed by Dunnett's multiple comparison tests.

TABLE 1: The effects of goose bone on relative organ weight.

\begin{tabular}{lcccc}
\hline Organs & Control & $30 \mathrm{mg} / \mathrm{kg}$ & $60 \mathrm{mg} / \mathrm{kg}$ & $120 \mathrm{mg} / \mathrm{kg}$ \\
\hline Heart & $0.384 \pm 0.01$ & $0.359 \pm 0.01$ & $0.367 \pm 0.01$ & $0.320 \pm 0.02$ \\
Kidney & $0.781 \pm 0.07$ & $0.807 \pm 0.03$ & $0.801 \pm 0.05$ & $0.795 \pm 0.07$ \\
Lung & $0.671 \pm 0.87$ & $0.713 \pm 0.14$ & $0.657 \pm 0.13$ & $0.634 \pm 0.02$ \\
Liver & $3.732 \pm 0.40$ & $3.890 \pm 0.26$ & $3.849 \pm 0.11$ & $3.742 \pm 0.45$ \\
Spleen & $0.226 \pm 0.01$ & $0.233 \pm 0.02$ & $0.232 \pm 0.01$ & $0.211 \pm 0.01$ \\
Caecum & $0.276 \pm 0.02$ & $0.265 \pm 0.04$ & $0.257 \pm 0.04$ & $0.255 \pm 0.05$ \\
Pancreas & $0.129 \pm 0.06$ & $0.156 \pm 0.04$ & $0.172 \pm 0.11$ & $0.124 \pm 0.06$ \\
Brain & $0.864 \pm 0.01$ & $0.874 \pm 0.05$ & $0.871 \pm 0.07$ & $0.829 \pm 0.15$ \\
Testes & $0.113 \pm 0.09$ & $0.121 \pm 0.08$ & $0.118 \pm 0.09$ & $0.097 \pm 0.06$ \\
Thymus & $0.133 \pm 0.01$ & $0.149 \pm 0.06$ & $0.139 \pm 0.07$ & $0.147 \pm 0.05$ \\
Caput & $0.287 \pm 0.07$ & $0.268 \pm 0.09$ & $0.254 \pm 0.05$ & $0.276 \pm 0.05$ \\
Cowper & $0.151 \pm 0.01$ & $0.159 \pm 0.01$ & $0.156 \pm 0.00$ & $0.152 \pm 0.01$ \\
gland & & & & \\
Stomach & $0.659 \pm 0.03$ & $0.630 \pm 0.01$ & $0.590 \pm 0.03$ & $0.608 \pm 0.02$ \\
Ovary & $0.075 \pm 0.03$ & $0.077 \pm 0.01$ & $0.070 \pm 0.02$ & $0.072 \pm 0.03$ \\
Fallopian & $0.306 \pm 0.01$ & $0.280 \pm 0.01$ & $0.282 \pm 0.01$ & $0.270 \pm 0.01$ \\
tube & & & & \\
\hline
\end{tabular}

Results are expressed as mean \pm SD $(n=8)$. Nonsignificant changes were found when all treatment groups were compared against the control group $(p<0.05)$ as determined using one-way ANOVA followed by Dunnett's multiple comparison tests.

[27]. TP and albumin activities are important indicators of liver function since they provide important information on the severity of liver necrosis and the capacity for protein synthesis [28]. In this study, daily oral administration of goose bone to rats at the three doses extracts no adverse effect on liver function markers. Furthermore, microscopic examinations of the rats' liver did not confer any cellular necrosis or centrilobular degenerative changes, infiltration of any inflammatory cells, or changes in cell sizes and architecture, thus further confirming its safety as also supported by the histopathological findings.

Urea, uric acid, and creatinine are waste products from protein metabolism that are eventually expelled via the
TABLE 2: The effects of goose bone on the percentage of water content of different organs.

\begin{tabular}{lcccc}
\hline Organs & Control & $30 \mathrm{mg} / \mathrm{kg}$ & $60 \mathrm{mg} / \mathrm{kg}$ & $120 \mathrm{mg} / \mathrm{kg}$ \\
\hline Heart & $52.90 \pm 1.13$ & $55.23 \pm 0.83$ & $53.95 \pm 2.42$ & $52.84 \pm 1.61$ \\
Kidney & $52.01 \pm 5.55$ & $52.32 \pm 8.15$ & $51.50 \pm 5.16$ & $53.93 \pm 3.76$ \\
Lung & $61.03 \pm 1.21$ & $61.84 \pm 3.45$ & $61.87 \pm 2.73$ & $59.75 \pm 1.62$ \\
Liver & $60.63 \pm 4.47$ & $54.40 \pm 5.11$ & $54.87 \pm 1.24$ & $53.71 \pm 1.38$ \\
Spleen & $47.75 \pm 0.67$ & $50.23 \pm 2.38$ & $51.38 \pm 3.38$ & $46.59 \pm 1.85$ \\
Caecum & $65.55 \pm 1.12$ & $63.52 \pm 1.92$ & $64.58 \pm 1.43$ & $63.82 \pm 1.73$ \\
Pancreas & $41.68 \pm 8.65$ & $40.26 \pm 2.81$ & $38.27 \pm 1.32$ & $37.81 \pm 0.37$ \\
Brain & $57.78 \pm 7.46$ & $53.74 \pm 5.82$ & $45.51 \pm 1.80$ & $32.37 \pm 10.58$ \\
Testes & $41.53 \pm 6.30$ & $55.32 \pm 3.87$ & $50.13 \pm 1.67$ & $31.47 \pm 3.49$ \\
Thymus & $59.58 \pm 1.12$ & $54.81 \pm 1.01$ & $58.22 \pm 1.13$ & $55.71 \pm 1.45$ \\
Caput & $61.30 \pm 1.89$ & $65.24 \pm 2.00$ & $64.22 \pm 1.65$ & $64.85 \pm 1.91$ \\
Cowper & $67.68 \pm 1.19$ & $62.13 \pm 2.68$ & $66.21 \pm 1.90$ & $65.98 \pm 2.07$ \\
gland & & & & \\
Stomach & $60.91 \pm 2.45$ & $58.75 \pm 1.95$ & $58.15 \pm 4.21$ & $56.26 \pm 1.23$ \\
Ovary & $56.65 \pm 2.76$ & $56.34 \pm 1.59$ & $54.20 \pm 1.39$ & $57.14 \pm 1.87$ \\
Fallopian & $39.01 \pm 0.01$ & $29.88 \pm 0.01$ & $28.13 \pm 0.01$ & $35.20 \pm 0.01$ \\
tube & & & & \\
\hline
\end{tabular}

Results are expressed as mean \pm SD $(n=8)$. Nonsignificant changes were found when all treatment groups were compared against the control group $(p<0.05)$ as determined using a one-way ANOVA followed by Dunnett's multiple comparison tests.

kidneys. Therefore, increase in their serum levels indicates functional damage to kidneys $[29,30]$. In our study, there were no significant changes in these renal biomarkers following administration of low to highest dose ranges of goose bone, indicating that goose bone is not toxic to the kidneys as further confirmed by histopathological observations of the kidney tissues.

Serum lipid profile is measured to predict hyperlipoproteinemia, triglyceridemia, liver obstruction, fatty liver disease, and pancreatitis [31,32]. Elevated levels of plasma triglyceride level are an important risk factor for cardiovascular disease [33] and are related to hypertension [34], diabetes mellitus, and obesity [35]. In fact, high plasma total cholesterol levels are linked to the development of atherosclerosis and other cardiovascular-related disease [36]. In addition, low HDL-C and high LDL-C are imperative predictors for cardiovascular disease [37] where high HDL-C shows a protective role by enhancing cholesterol transport via collection of excess cholesterol from peripheral tissue. On the other hand, atherogenic indices (CRR, ACC, RIP, and CRI-2) are derived from lipid panels where the increase in the atherogenic indices is associated with the development of cardiovascular diseases. In our study, goose bone significantly reduced serum TG levels and AIP at all three administered doses while other parameters of lipid profile and atherogenic indices remain unchanged. In some previous reports, natural products that are high in omega-3 fatty acids have been reported to reduce TG levels. For example, Shearer et al. suggested that fish oil containing omega-3 fatty acid can reduce TG level [38] as also with goose bone which is high in lipid content that is healthy to the body. Similarly, since AIP is a logarithmic ratio of TG and HDL-C, when TG levels are reduced, AIP is also decreased as seen in this case. 
TABLE 3: The effects of goose bone on the hematological parameters in whole blood.

\begin{tabular}{|c|c|c|c|c|}
\hline Hematological parameters & Control & $30 \mathrm{mg} / \mathrm{kg}$ & $60 \mathrm{mg} / \mathrm{kg}$ & $120 \mathrm{mg} / \mathrm{kg}$ \\
\hline WBC $\left(\times 10^{9} / \mathrm{L}\right)$ & $6.15 \pm 1.31$ & $6.61 \pm 0.71$ & $6.40 \pm 1.30$ & $4.87 \pm 1.03$ \\
\hline NEUT $(\%)$ & $15.75 \pm 1.89$ & $14.25 \pm 2.50$ & $15.75 \pm 1.89$ & $19.75 \pm 3.59$ \\
\hline LYMPH (\%) & $81.25 \pm 2.87$ & $84.25 \pm 2.63$ & $81.25 \pm 2.87$ & $76.75 \pm 3.86$ \\
\hline Mono (\%) & $1.65 \pm 0.39$ & $1.35 \pm 0.17$ & $1.65 \pm 0.39$ & $1.28 \pm 0.22$ \\
\hline Eo $(\%)$ & $1.02 \pm 0.36$ & $1.30 \pm 0.29$ & $1.18 \pm 0.35$ & $1.05 \pm 0.13$ \\
\hline $\mathrm{RBC}\left(\times 10^{12} / \mathrm{L}\right)$ & $6.12 \pm 2.36$ & $6.11 \pm 2.36$ & $6.12 \pm 2.36$ & $7.70 \pm 0.49$ \\
\hline $\mathrm{HGB}(\mathrm{g} / \mathrm{dl})$ & $13.80 \pm 1.11$ & $13.80 \pm 1.17$ & $13.80 \pm 1.12$ & $14.40 \pm 0.74$ \\
\hline $\operatorname{ESR}(\mathrm{mm})$ & $3.40 \pm 0.11$ & $4.10 \pm 0.31$ & $3.90 \pm 0.42$ & $4.00 \pm 0.34$ \\
\hline HCT (\%) & $35.85 \pm 13.85$ & $35.85 \pm 13.85$ & $35.85 \pm 13.85$ & $44.35 \pm 2.79$ \\
\hline MCV (fL) & $58.70 \pm 1.24$ & $58.70 \pm 1.24$ & $58.70 \pm 1.24$ & $57.63 \pm 1.31$ \\
\hline $\mathrm{MCH}(\mathrm{pg})$ & $18.70 \pm 0.76$ & $18.70 \pm 0.76$ & $18.70 \pm 0.76$ & $18.70 \pm 0.26$ \\
\hline $\mathrm{MCHC}(\mathrm{g} / \mathrm{dl})$ & $31.88 \pm 1.23$ & $31.88 \pm 1.23$ & $31.88 \pm 1.23$ & $32.50 \pm 0.85$ \\
\hline PLT $\left(\times 10^{9} / \mathrm{L}\right)$ & $692.00 \pm 267.70$ & $692.00 \pm 267.71$ & $692.00 \pm 267.71$ & $803.75 \pm 86.32$ \\
\hline RDW-SD (fL) & $27.70 \pm 2.32$ & $27.70 \pm 2.32$ & $27.70 \pm 2.32$ & $27.53 \pm 3.12$ \\
\hline RDW-CV (\%) & $14.25 \pm 2.18$ & $14.25 \pm 2.18$ & $14.25 \pm 2.18$ & $15.28 \pm 2.46$ \\
\hline PDW (fL) & $8.80 \pm 0.27$ & $8.80 \pm 0.27$ & $8.80 \pm 0.27$ & $8.93 \pm 0.33$ \\
\hline MPV (fL) & $8.40 \pm 0.54$ & $8.40 \pm 0.51$ & $8.40 \pm 0.51$ & $8.18 \pm 0.26$ \\
\hline P-LCR (\%) & $12.80 \pm 2.80$ & $12.80 \pm 2.79$ & $12.80 \pm 2.79$ & $11.30 \pm 1.90$ \\
\hline PCT (\%) & $0.58 \pm 0.21$ & $0.58 \pm 0.21$ & $0.58 \pm 0.21$ & $0.66 \pm 0.09$ \\
\hline
\end{tabular}

Results are expressed as mean \pm SD $(n=8)$. HGB: hemoglobin, HCT: hematocrit, MCV: mean corpuscular volume, MCH: mean corpuscular hemoglobin, MCHC: mean corpuscular hemoglobin concentration, PLT: platelets, RDW-SD: red cell distribution width-standard deviation, RDW-CV: red cell distribution width-coefficient of variation, PDW-CV: platelets distribution width, ESR: erythrocyte sedimentation rate, MPV: mean platelets volume, P-LCR: platelets larger cell ratio, and PCT: procalcitonin.

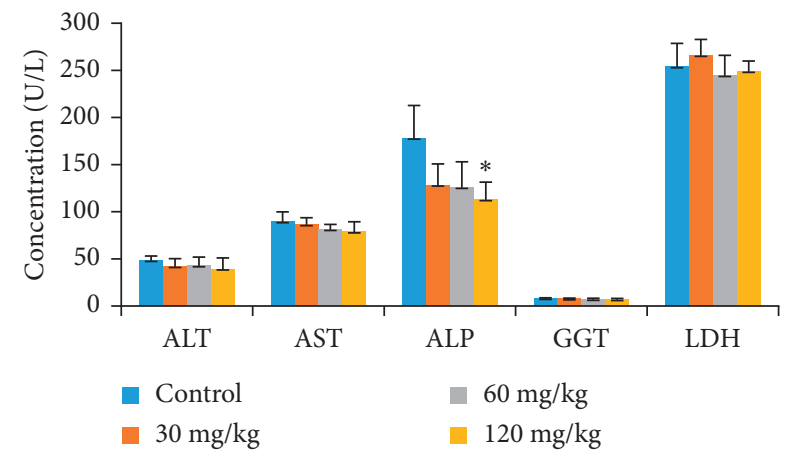

FIgURE 2: The effects of goose bone on serum hepatic marker enzymes. Results are expressed as mean $\pm \operatorname{SD}(n=8)$. * denotes level of significant difference when compared to the control group as determined using a one-way ANOVA followed by Dunnett's multiple comparison tests.

Serum amylase and lipase are two major digestive enzymes in animals. Amylase acts on starch in food, breaking it down into smaller carbohydrate molecules while lipase breaks down dietary fats into smaller molecules called fatty acids and glycerol. Both are important biomarkers for diagnosis of acute pancreatitis as they are synthesized and secreted into the intestinal lumen to be released into the circulation in catalytically active forms [39]. However, acute pancreatitis lipase is a more reliable diagnostic marker than amylase for its lipolytic activity and can be assayed very rapidly $[40,41]$. The blood glucose level can indicate body utilization of glucose. Estimation of blood glucose level is the first step in diagnoses of diabetes mellitus, since it is a reliable marker, the levels of which are increased in diabetics following meal intake [42].
TABLE 4: The effects of goose bone on serum total bilirubin (TB), total protein (TP), albumin (ALB), globulin (GLB), and albumin/ globulin $(\mathrm{A} / \mathrm{G})$ ratio.

\begin{tabular}{lcccc}
\hline $\begin{array}{l}\text { Biochemical } \\
\text { parameters }\end{array}$ & Control & $30 \mathrm{mg} / \mathrm{kg}$ & $60 \mathrm{mg} / \mathrm{kg}$ & $120 \mathrm{mg} / \mathrm{kg}$ \\
\hline TB $(\mathrm{mg} / \mathrm{dl})$ & $0.20 \pm 0.07$ & $0.17 \pm 0.04$ & $0.20 \pm 0.07$ & $0.22 \pm 0.04$ \\
TP $(\mathrm{g} / \mathrm{L})$ & $5.45 \pm 0.33$ & $5.48 \pm 0.27$ & $5.35 \pm 0.44$ & $5.34 \pm 0.38$ \\
ALB $(\mathrm{g} / \mathrm{L})$ & $2.70 \pm 0.14$ & $2.66 \pm 0.14$ & $2.56 \pm 0.30$ & $2.71 \pm 0.21$ \\
GLB $(\mathrm{g} / \mathrm{L})$ & $2.75 \pm 0.18$ & $2.82 \pm 0.15$ & $2.79 \pm 0.23$ & $2.63 \pm 0.17$ \\
A/G & $0.98 \pm 0.01$ & $0.94 \pm 0.04$ & $0.92 \pm 0.10$ & $1.02 \pm 0.02$ \\
\hline
\end{tabular}

Results are expressed as mean \pm SD $(n=6)$. No significant changes were established when all treatment groups were compared against the control group by using one-way ANOVA followed by Dunnett's multiple comparison tests.

Another highlight of our research was the histopathological study that further confirmed the nontoxic effect of goose bone. Toxic substances cause degenerative necrosis of hepatocytes, vacuolization of the hepatic lobules [43], degeneration of the kidney glomeruli with inflammatory infiltrates [44], massive separation of cardiac muscle necrotic damage to the myocytes of the heart tissue [45] and islets of Langerhans of pancreas [46], neuronal degeneration of brain [47], damage of alveoli of lung [48], inflammation of the mucous layers of stomach [49], and damage of the hematopoietic and lymphoid elements of spleen [50]. The histopathological findings of the major organs provide a further strong support on its safety. Overall, our study confirms that goose bone is nontoxic, safe, and beneficial to some extent (especially on the liver and hematological profiles) to be consumed at the normal doses taken in humans.

Our study has some limitations. Since the effects of goose bone were investigated only for 21 days, its subchronic and 
TABLE 5: The effects of goose bone on serum renal markers.

\begin{tabular}{|c|c|c|c|c|}
\hline Biochemical parameters & Control & $30 \mathrm{mg} / \mathrm{kg}$ & $60 \mathrm{mg} / \mathrm{kg}$ & $120 \mathrm{mg} / \mathrm{kg}$ \\
\hline Creatinine $(\mathrm{mmol} / \mathrm{L})$ & $0.35 \pm 0.02$ & $0.37 \pm 0.04$ & $0.39 \pm 0.03$ & $0.36 \pm 0.01$ \\
\hline Urea $(\mathrm{mmol} / \mathrm{L})$ & $35.10 \pm 1.64$ & $28.20 \pm 0.51$ & $39.72 \pm 5.07$ & $36.81 \pm 6.23$ \\
\hline $\mathrm{UA}(\mathrm{mmol} / \mathrm{L})$ & $0.45 \pm 0.07$ & $0.43 \pm 0.09$ & $0.29 \pm 0.14$ & $0.33 \pm 0.11$ \\
\hline $\mathrm{Na}^{+}(\mathrm{mmol} / \mathrm{L})$ & $138.25 \pm 6.49$ & $141.25 \pm 0.82$ & $141.00 \pm 3.67$ & $145.50 \pm 4.97$ \\
\hline $\mathrm{K}^{+}(\mathrm{mmol} / \mathrm{L})$ & $3.72 \pm 0.31$ & $4.02 \pm 1.23$ & $4.22 \pm 0.64$ & $4.62 \pm 0.92$ \\
\hline $\mathrm{Cl}^{-}(\mathrm{mmol} / \mathrm{L})$ & $101.00 \pm 5.74$ & $104.75 \pm 3.89$ & $104.25 \pm 2.58$ & $107.00 \pm 3.53$ \\
\hline $\mathrm{PO}^{4+}(\mathrm{mmol} / \mathrm{L})$ & $8.20 \pm 0.75$ & $9.45 \pm 1.67$ & $8.61 \pm 1.47$ & $8.30 \pm 1.06$ \\
\hline $\mathrm{Ca}^{2+}(\mathrm{mmol} / \mathrm{L})$ & $10.26 \pm 0.78$ & $11.03 \pm 1.09$ & $11.05 \pm 1.12$ & $11.47 \pm 0.52$ \\
\hline $\mathrm{Mg}^{2+}(\mathrm{mmol} / \mathrm{L})$ & $0.75 \pm 0.06$ & $0.69 \pm 0.07$ & $0.80 \pm 0.11$ & $0.78 \pm 0.08$ \\
\hline
\end{tabular}

Results are expressed as mean $\pm \mathrm{SD}(n=8) .{ }^{*}$ The level of significant difference when compared to the control group as determined by using one-way ANOVA followed by Dunnett's multiple comparison tests.

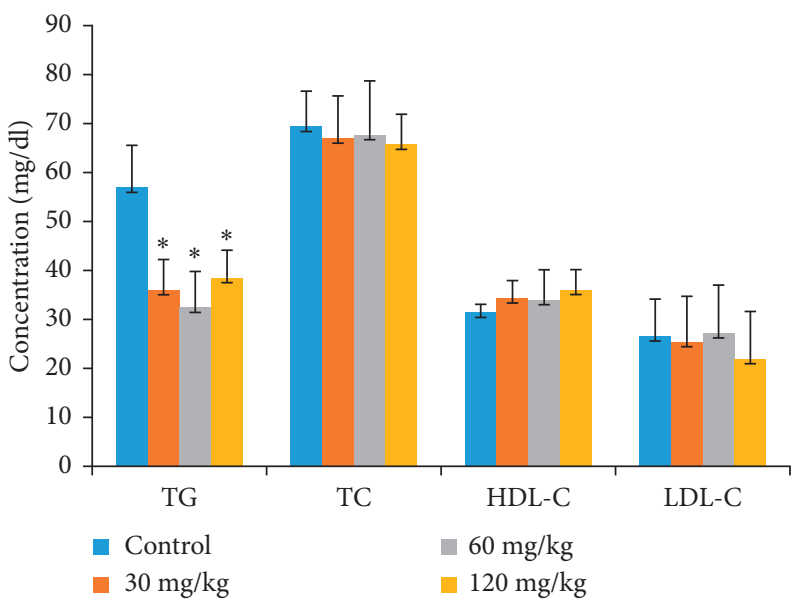

Figure 3: The effects of goose bone on lipid profile. Results are expressed as mean $\pm \operatorname{SD}(n=8) .{ }^{*}$ denotes level of significant difference when compared to the control group as determined using a one-way ANOVA followed by Dunnett's multiple comparison tests.

TABLE 6: The effects of goose bone on atherogenic indices.

\begin{tabular}{lcccc}
\hline Biochemical parameters & Control & $30 \mathrm{mg} / \mathrm{kg}$ & $60 \mathrm{mg} / \mathrm{kg}$ & $120 \mathrm{mg} / \mathrm{kg}$ \\
\hline CRR & $2.21 \pm 0.17$ & $1.96 \pm 0.26$ & $2.02 \pm 0.30$ & $1.86 \pm 0.34$ \\
ACC & $1.20 \pm 0.17$ & $0.96 \pm 0.26$ & $1.02 \pm 0.30$ & $0.86 \pm 0.34$ \\
AIP & $0.25 \pm 0.08$ & $0.21 \pm 0.01^{*}$ & $0.20 \pm 0.07^{*}$ & $0.18 \pm 0.02^{*}$ \\
CRI-2 & $0.84 \pm 0.22$ & $0.75 \pm 0.28$ & $0.83 \pm 0.28$ & $0.64 \pm 0.30$ \\
\hline
\end{tabular}

Results are expressed as mean $\pm \mathrm{SD}(n=8) .{ }^{*}$ denotes level of significant difference when compared to the control group as determined using a one-way ANOVA followed by Dunnett's multiple comparison tests.

TABle 7: The effects of goose bone on pancreatic function.

\begin{tabular}{lcccc}
\hline Biochemical parameters & Control & $30 \mathrm{mg} / \mathrm{kg}$ & $60 \mathrm{mg} / \mathrm{kg}$ & $120 \mathrm{mg} / \mathrm{kg}$ \\
\hline Amylase (U/L) & $2145.25 \pm 403.83$ & $2080.00 \pm 565.73$ & $2196.00 \pm 615.50$ & $2070.50 \pm 388.30$ \\
Lipase (U/L) & $27.13 \pm 2.61$ & $29.43 \pm 2.09$ & $24.56 \pm 2.91$ & $25.86 \pm 3.60$ \\
Glucose (mmol/L) & $10.27 \pm 0.88$ & $10.59 \pm 0.47$ & $9.47 \pm 1.11$ & $9.64 \pm 1.54$ \\
\hline
\end{tabular}

Results are expressed as mean $\pm \mathrm{SD}(n=8)$. No significant changes were found when all treatment groups were compared with the control group $(p<0.05)$ as determined by using one-way ANOVA followed by Dunnett's multiple comparison tests.

chronic effects were not investigated. Therefore, future studies should be conducted to investigate the long-term effects of goose bone. Additionally, the dose can be increased based on the Organization for Corporation and Development (OECD) guideline in order to have a more rigorous test. Finally, the use of Hematoxylin-Eosin-Saffron 


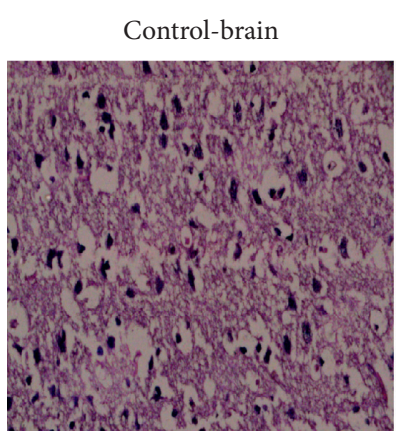

Goose bone-brain

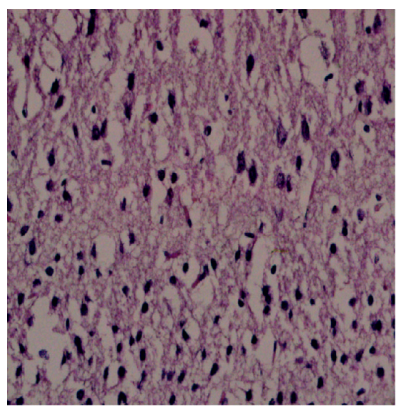

Control-liver

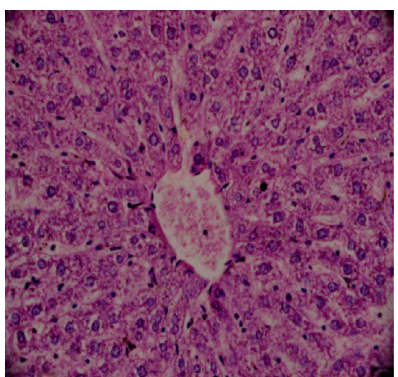

Goose bone-liver

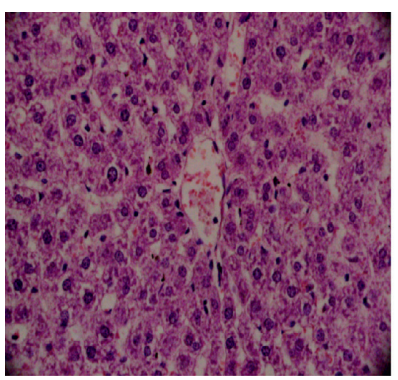

Control-heart

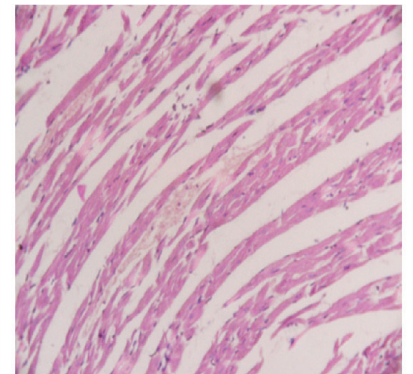

Goose bone-heart

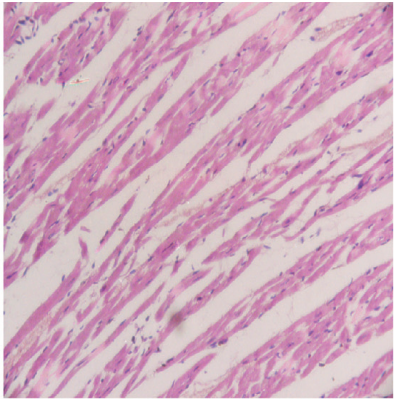

(a)

Control-pancreas

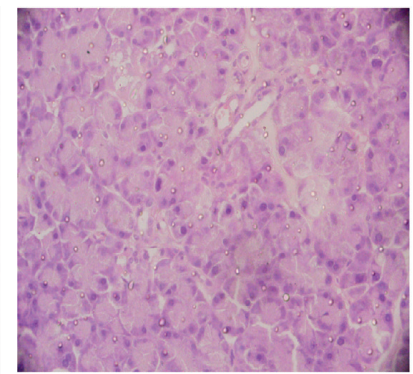

Goose bone-pancreas

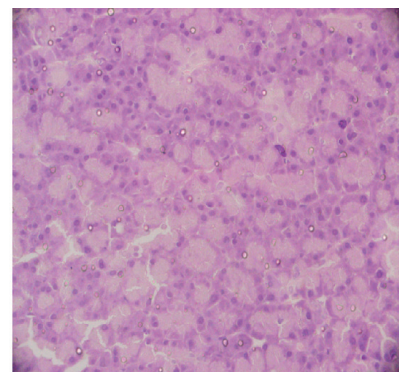

Control-lung

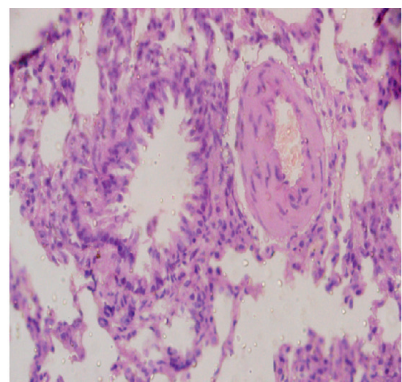

Goose bone-lung
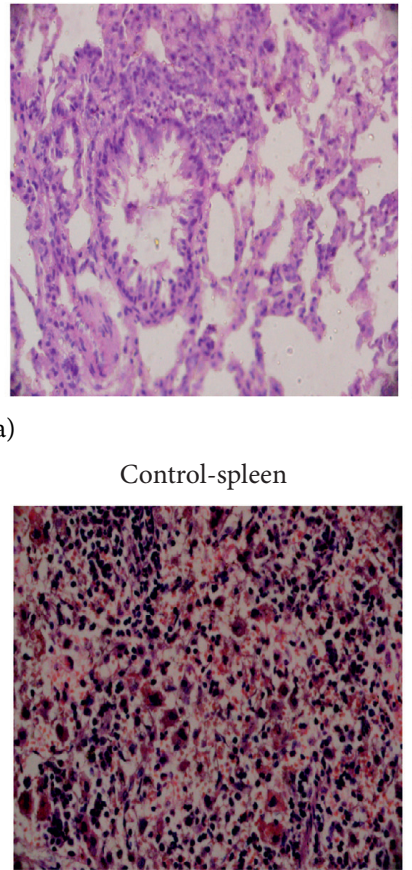

Goose bone-spleen

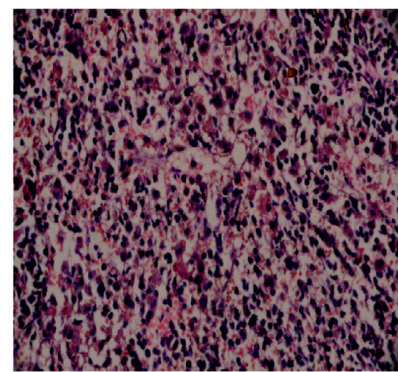

Control-kidney

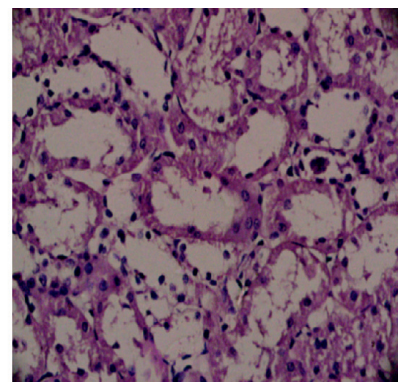

Goose bone-kidney

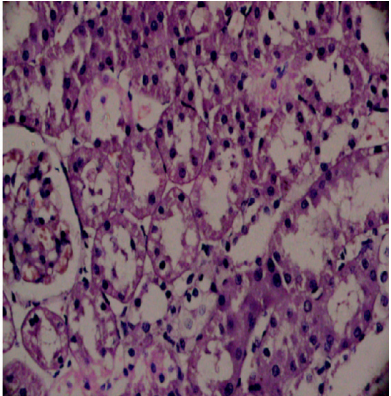

Control-stomach

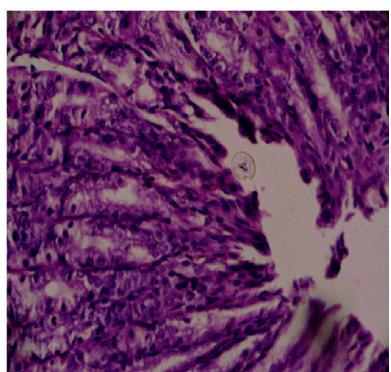

Goose bone-stomach

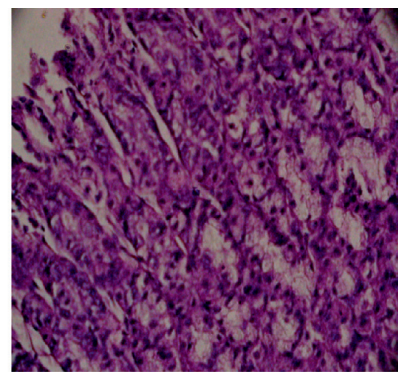

(b)

FiguRE 4: Histopathological photomicrographs of control and treatment groups $(120 \mathrm{mg} / \mathrm{kg}$ ) (40x magnification, scale bar: $20 \mu \mathrm{m})$. No morphological and pathological changes were observed between the control and goose bone-administered groups.

may be more ideal in histopathological analysis since saffron stains collagen fibers in the tissues besides contributing to complete removal of eosin.

\section{Conclusion}

Goose bone is nontoxic and is safe for consumption at the investigated doses. Oral administration of goose bone up to $120 \mathrm{mg} / \mathrm{kg}$ did not significantly affect body weight, relative organ weight profile, and percentage water content of vital organs as well as physiological, hematological, and biochemical abnormalities over the three-week treatment period. The histopathological findings on the major organs further confirm its safety. Additionally, goose bone may ameliorate high triglyceride and ALPrelated disorders. 


\section{Data Availability}

The data used to support the findings of this study are enclosed within the article. Additional data are accessible from the corresponding author upon request.

\section{Conflicts of Interest}

The goose bone capsules studied in this research were provided by Star Goose Enterprise, who hold a patent (PI2017701257) and provided financial support.

\section{Acknowledgments}

We would like to acknowledge Madam Roxhana Omar, Managing Director, Star Goose Enterprise, Pasir Mas, Kelantan, Malaysia, for providing financial support and goose bone capsules used in this study.

\section{References}

[1] A. Flynn, "The role of dietary calcium in bone health," Proceedings of the Nutrition Society, vol. 62, no. 4, pp. 851-858, 2003.

[2] G. E. Gibson and C. Peterson, "Calcium and the aging nervous system,” Neurobiology of Aging, vol. 8, no. 4, pp. 329-343, 1987.

[3] J. Z. Ilich and J. E. Kerstetter, "Nutrition in bone health revisited: a story beyond calcium," Journal of the American College of Nutrition, vol. 19, no. 6, pp. 715-737, 2000.

[4] M. Ali et al., "Antioxidant potential, subacute toxicity, and beneficiary effects of methanolic extract of pomelo (Citrus grandis L. Osbeck) in long evan rats," Journal of Toxicology, vol. 2019, p. 12, 2019.

[5] S. Reagan-Shaw, M. Nihal, and N. Ahmad, "Dose translation from animal to human studies revisited," The FASEB Journal, vol. 22, no. 3, pp. 659-661, 2008.

[6] D. Ringer, "Hematology and clinical biochemistry," in The Laboratory Rat, pp. 105-121, Academic Press, Cambridge, MA, USA, 1979.

[7] Z. Liu et al., "The subchronic toxicity of hydroxysafflor yellow A of 90 days repeatedly intraperitoneal injections in rats," Toxicology, vol. 203, no. 1-3, pp. 139-143, 2004.

[8] J. M. Peters and E. M. Boyd, "Organ weights and water levels of the rat following reduced food intake," The Journal of Nutrition, vol. 90, no. 4, pp. 354-360, 1966.

[9] W. T. Friedewald, R. I. Levy, and D. S. Fredrickson, "Estimation of the concentration of low-density lipoprotein cholesterol in plasma, without use of the preparative ultracentrifuge," Clinical Chemistry, vol. 18, no. 6, pp. 499-502, 1972.

[10] D. M. Martirosyan, L. A. Miroshnichenko, S. N. Kulakova, A. V. Pogojeva, and V. I. Zoloedov, "Amaranth oil application for coronary heart disease and hypertension," Lipids in Health and Disease, vol. 6, no. 1, p. 1, 2007.

[11] A. Brehm, "Relationship between serum lipoprotein ratios and insulin resistance in obesity," Clinical Chemistry, vol. 50, no. 12, pp. 2316-2322, 2004.

[12] M. Dobiášová, "Atherogenic index of plasma [log (triglycerides/HDL-cholesterol)]: theoretical and practical implications," Clinical Chemistry, vol. 7, pp. 1113-1115, 2004.
[13] W. P. Castelli, R. D. Abbott, and P. M. McNamara, "Summary estimates of cholesterol used to predict coronary heart disease," Circulation, vol. 67, no. 4, pp. 730-734, 1983.

[14] H. M. Carleton, R. A. B. Drury, and E. A. Wallington, Carleton's Histological Technique, Oxford University Press, Cary, NC, USA, 1980.

[15] E. Dybing et al., "Hazard characterisation of chemicals in food and diet: dose response, mechanisms and extrapolation issues," Food and Chemical Toxicology, vol. 40, no. 2-3, pp. 237-282, 2002.

[16] A. Dal Bosco, Z. Gerencsér, Z. Szendrő et al., "Effect of dietary supplementation of Spirulina (Arthrospira platensis) and Thyme (Thymus vulgaris) on rabbit meat appearance, oxidative stability and fatty acid profile during retail display," Meat Science, vol. 96, no. 1, pp. 114-119, 2014.

[17] R. Ross, "Atherosclerosis—an inflammatory disease," New England Journal of Medicine, vol. 340, no. 2, pp. 115-126, 1999.

[18] E. Tousson, M. El-Moghazy, and E. El-Atrsh, "The possible effect of diets containing Nigella sativa and Thymus vulgaris on blood parameters and some organs structure in rabbit," Toxicology and Industrial Health, vol. 27, no. 2, pp. 107-116, 2011.

[19] M. Gawaz, H. Langer, and A. E. May, "Platelets in inflammation and atherogenesis," Journal of Clinical Investigation, vol. 115, no. 12, pp. 3378-3384, 2005.

[20] E. Vagdatli, E Gounari, E Lazaridou, E Katsibourlia, F Tsikopoulou, and I Labrianou, "Platelet distribution width: a simple, practical and specific marker of activation of coagulation," Hippokratia, vol. 14, no. 1, pp. 28-32, 2010.

[21] A. Ihara, T. Kawamoto, K. Matsumoto, S. Shouno, T. Morimoto, and Y. Noma, "Relationship between hemostatic factors and the platelet index in patients with ischemic heart disease," Pathophysiology of Haemostasis and Thrombosis, vol. 35, no. 5, pp. 388-391, 2006.

[22] F. M. El-Demerdash, "Antioxidant effect of vitamin E and selenium on lipid peroxidation, enzyme activities and biochemical parameters in rats exposed to aluminium," Journal of Trace Elements in Medicine and Biology, vol. 18, no. 1, pp. 113-121, 2004.

[23] P. L. Wolf, "Biochemical diagnosis of liver disease," Indian Journal of Clinical Biochemistry, vol. 14, no. 1, pp. 59-90, 1999.

[24] N. Anderson and J. Borlak, "Molecular mechanisms and therapeutic targets in steatosis and steatohepatitis," Pharmacological Reviews, vol. 60, no. 3, pp. 311-357, 2008.

[25] B. R. Thapa and A. Walia, "Liver function tests and their interpretation," The Indian Journal of Pediatrics, vol. 74, no. 7, pp. 663-671, 2007.

[26] A. Singh, T. K. Bhat, and O. P. Sharma, "Clinical biochemistry of hepatotoxicity," Journal of Clinical Toxicology, vol. 4, no. 1, pp. 1-19, 2011.

[27] P. T. Giboney, "Mildly elevated liver transaminase levels in the asymptomatic patient," American Family Physician, vol. 71, no. 6, pp. 1105-1110, 2005.

[28] E. M. Tanvir, R. Afroz, M. A. Z. Chowdhury et al., "Honey has a protective effect against chlorpyrifos-induced toxicity on lipid peroxidation, diagnostic markers and hepatic histoarchitecture," European Journal of Integrative Medicine, vol. 7, no. 5, pp. 525-533, 2015.

[29] A. Monira, K. El, and Z. Naima, "Evaluation of protective and antioxidant activity of thyme (Thymus vulgaris) extract on paracetamol-induced toxicity in rats," Australian Journal of Basic and Applied Sciences, vol. 6, no. 7, pp. 467-474, 2012. 
[30] W. Van Biesen, R. Vanholder, and N. Lameire, "Defining acute renal failure: RIFLE and beyond: table 1," Clinical Journal of the American Society of Nephrology, vol. 1, no. 6, pp. 1314-1319, 2006.

[31] M. Ali, S. Paul, E. M. Tanvir et al., "Antihyperglycemic, antidiabetic, and antioxidant effects of Garcinia pedunculata in rats," Evidence-Based Complementary and Alternative Medicine, vol. 2017, Article ID 2979760, 15 pages, 2017.

[32] C. Matteoni, Z. Younossi, T. Gramlich, N. Boparai, Y. Liu, and A. Mccullough, "Nonalcoholic fatty liver disease: a spectrum of clinical and pathological severity," Gastroenterology, vol. 116, no. 6, pp. 1413-1419, 1999.

[33] P. McBride, "Triglycerides and risk for coronary artery disease," Current Atherosclerosis Reports, vol. 10, no. 5, pp. 386-390, 2008.

[34] J. Zicha, J. Kuneš, and M.-A. Devynck, Abnormalities of Membrane Function and Lipid Metabolism in Hypertension: A Review, Oxford University Press, Oxford, UK, 1999.

[35] G. Shen, "Lipid disorders in diabetes mellitus and current management," Current Pharmaceutical Analysis, vol. 3, no. 1, pp. 17-24, 2007.

[36] O. Ademuyiwa, R. Ugbaja, F. Idumebor, and O. Adebawo, "Plasma lipid profiles and risk of cardiovascular disease in occupational lead exposure in Abeokuta, Nigeria," Lipids in Health and Disease, vol. 4, no. 1, p. 19, 2005.

[37] A. H. Lichtenstein, L. J. Appel, M. Brands et al., "Diet and lifestyle recommendations revision 2006," Circulation, vol. 114, no. 1, pp. 82-96, 2006.

[38] G. C. Shearer, O. V. Savinova, and W. S. Harris, "Fish oil-how does it reduce plasma triglycerides?," Biochimica et Biophysica Acta (BBA)-Molecular and Cell Biology of Lipids, vol. 1821, no. 5, pp. 843-851, 2012.

[39] J. L. Rosenblum, "Serum lipase activity is increased in disease states other than acute pancreatitis: amylase revisited," Clinical Chemistry, vol. 37, no. 3, pp. 315-316, 1991.

[40] P.-A. Clavien, S. Burgan, and A. R. Moossa, "Serum enzymes and other laboratory tests in acute pancreatitis," British Journal of Surgery, vol. 76, no. 12, pp. 1234-1243, 1989.

[41] M. Ventrucci, R. Pezzilli, L. Gullo, L. Platé, G. Sprovieri, and L. Barbara, "Role of serum pancreatic enzyme assays in diagnosis of pancreatic disease," Digestive Diseases and Sciences, vol. 34, no. 1, pp. 39-45, 1989.

[42] K. G. M. M. Alberti, P. Z. Zimmet, and WHO Consultation, "Definition, diagnosis and classification of diabetes mellitus and its complications. Part 1: diagnosis and classification of diabetes mellitus. Provisional report of a WHO consultation," Diabetic Medicine, vol. 15, no. 7, pp. 539-553, 1998.

[43] L. Mannelli, S. Kim, C. H. Hajdu, J. S. Babb, T. W. I. Clark, and B. Taouli, "Assessment of tumor necrosis of hepatocellular carcinoma after chemoembolization: diffusion-weighted and contrast-enhanced MRI with histopathologic correlation of the explanted liver," American Journal of Roentgenology, vol. 193, no. 4, pp. 1044-1052, 2009.

[44] C. Langenberg, S. M. Bagshaw, C. N. May, and R. Bellomo, "The histopathology of septic acute kidney injury: a systematic review," Critical Care, vol. 12, no. 2, p. R38, 2008.

[45] M. C. Fishbein, D. Maclean, and P. R. Maroko, "The histopathologic evolution of myocardial infarction," Chest, vol. 73, no. 6, pp. 843-849, 1978.

[46] M. F. McLoughlin, R. N. Nelson, J. I. McCormick, H. M. Rowley, and D. B. Bryson, "Clinical and histopathological features of naturally occurring pancreas disease in farmed Atlantic salmon, Salmo salar L.," Journal of Fish Diseases, vol. 25, no. 1, pp. 33-43, 2002.
[47] W. D. Dietrich, O. Alonso, R. Busto, M. Y.-T. Globus, and M. D. Ginsberg, "Post-traumatic brain hypothermia reduces histopathological damage following concussive brain injury in the rat," Acta Neuropathologica, vol. 87, no. 3, pp. 250-258, 1994.

[48] S. Sugaar and H. H. Leveen, "A histopathologic study on the effects of radiofrequency thermotherapy on malignant tumors of the lung," Cancer, vol. 43, no. 2, pp. 767-783, 1979.

[49] K. Terao, E. Ito, Y. Sakamaki, K. Igarashi, A. Yokoyama, and T. Yasumoto, "Histopathological studies of experimental marine toxin poisoning. II. The acute effects of maitotoxin on the stomach, heart and lymphoid tissues in mice and rats," Toxicon, vol. 26, no. 4, pp. 395-402, 1988.

[50] A. W. Suttie, "Histopathology of the spleen," Toxicologic Pathology, vol. 34, no. 5, pp. 466-503, 2006. 